\title{
Type-D personality: a predictor of quality of life and coronary heart disease
}

\author{
T. Saeed, ${ }^{1}$ G.S.K. Niazi ${ }^{7}$ and S. Almas ${ }^{2}$
}

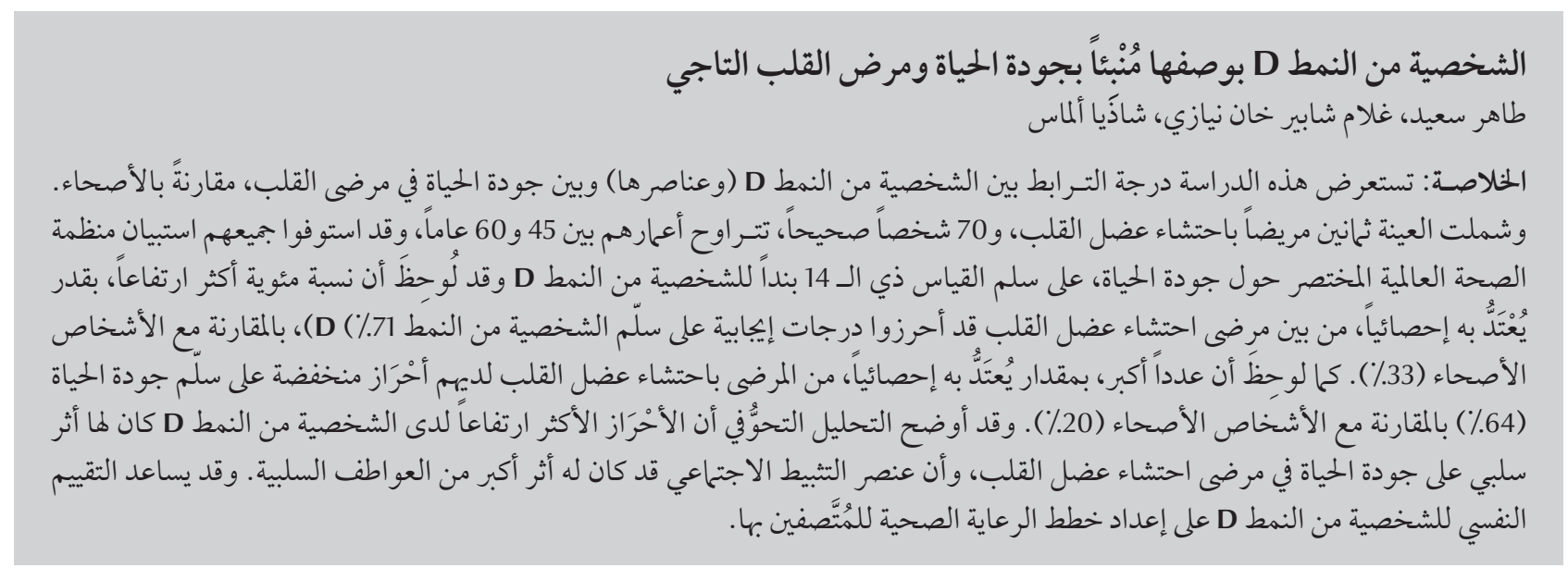

ABSTRACT The present study examined the association of type-D personality (and its components) with quality of life in cardiac patients compared with healthy people. A sample of 80 patients with myocardial infarction (MI) and 70 healthy people aged 45-60 years completed the WHO quality of life brief questionnaire and the 14-item type-D personality scale. A significantly higher percentage of the MI group scored positive for type-D personality compared with healthy individuals (71\% versus 33\%). Significantly more MI patients had low quality of life scores than did healthy individuals (64\% versus 20\%). Regression analysis showed that higher scores on type-D personality had a negative impact on quality of life in MI patients and that the social inhibition component had a greater impact than negative affectivity. Psychological assessment for type-D personality may be helpful in developing health care plans.

\section{Personnalité de type $\mathrm{D}$ : un facteur prédictif de la qualité de vie et de coronaropathie}

RÉSUMÉ La présente étude a examiné I'association de la personnalité de type D (et ses composantes) à la qualité de vie des patients atteints de troubles cardiaques comparativement à la qualité de vie des personnes en bonne santé. Un échantillon de 80 personnes atteintes d'un infarctus du myocarde et de 70 personnes en bonne santé, âgées de 45 à 60 ans, a rempli le questionnaire de l'OMS sur la qualité de vie dans sa version abrégée et l'échelle en 14 items sur la personnalité de type D. Un pourcentage significativement plus élevé du groupe de patients atteints d'infarctus de myocarde a obtenu un résultat positif pour la personnalité de type D par rapport au pourcentage du groupe des personnes en bonne santé (71\% contre $33 \%$ ). Les patients atteints d'infarctus du myocarde étaient plus nombreux à obtenir des résultats faibles en termes de qualité de vie que les personnes en bonne santé (64\% contre $20 \%$ ). L'analyse de régression a montré que les scores les plus élevés pour la personnalité de type D avaient un impact négatif sur la qualité de vie des patients atteints d'infarctus du myocarde et que la composante de l'inhibition sociale avait une influence plus forte que l'affectivité négative. Une évaluation psychologique permettant de dépister la personnalité de type D peut être utile pour l'élaboration de programmes de soins de santé. 


\section{Introduction}

The incidence of cardiovascular disease (CVD) is increasing rapidly in the developing world and CVD is expected to become the leading cause of death in future decades [1]. The South-Asian countries contribute the highest proportion of CVD compared with any other region globally [2] and in Pakistan surveys indicate a very high prevalence of CVD with over $20 \%$ of the population affected, and rapidly rising rates in urban areas [3]. Acute myocardial infarction (MI) is most frequently (but not always) a manifestation of coronary heart disease (CHD).

Psychosocial factors such as healthrelated beliefs, social support, coping style and personality type are important predictors of health or illness. For example, individuals with different personality characteristics have been found to differ in the way they explain their symptoms and seek medical assistance. Type-D personality is a construct characterized by the joint tendency to experience negative emotions and to inhibit these emotions, while avoiding social contacts with others [4]. Grande et al. identified the type-D personality pattern as consisting of 2 components: negative affectivity (a tendency to experience negative emotions including depressed mood, anxiety, anger and hostile feelings) and social inhibition (avoidance of potential dangers involved in social interactions such as disapproval or non-reward by others) [5-8].

Inhibition of emotional expression in type-D people puts them at greater risk of serious health problems, including hypertension, CHD and other physical and mental disorders. Patients with type-D personality may be more inclined to engage in unhealthy behaviours, such as smoking, drinking alcohol, physical inactivity and not adhering to dietary advice. They may refrain from consulting a physician, and if they do so, are less likely to comply with the advised treatment. Type-D personality may be prone to emotional distress such as anxiety, depression and anger in general and myocardial ischaemic events in particular [9]. The estimated risk of cardiac events was found to be 4.7 times greater for type-D patients than for non-type-D patients [5].

Poor health has a potent effect on an individual's quality of life (QOL) [10]. The QOL concept incorporates a humanistic view of health, in which optimal autonomy, personal strength and positive meaning of life are central components [11]. The psychological, social, physical and environmental domains of QOL have a major impact on the perceived health of CHD patients [10]. In clinical settings, type-D personality and poor QOL are associated with high mortality in cardiac patients [12]. There is little published research on CVD from Pakistan [13] and even less about its relationship with psychological factors, personality characteristics and QOL. QOL has been studied in Pakistan with reference to stroke patients and diabetics [14]. The aims of the present empirical study were to investigate whether type-D personality and its 2 components (negative affectivity and social inhibition) prevail among MI patients in Pakistan as compared to healthy individuals and whether these have a negative impact on QOL among cardiac patients.

\section{Methods}

The study was conducted from May 2005 to August 2007.

\section{Sample}

The patients were selected from the outpatient department of a local cardiac centre of Rawalpindi, Pakistan. A total of $125 \mathrm{MI}$ patients were initiallyselected for the study using convenience sampling. Out of these, 80 patients fulfilled the inclusion criteria; 45 patients dropped out, as 18 refused to participate in the study and 27 did not fulfil the required criteria. Patients were those in the age range 45-60 years who were diagnosed for the first time with MI by a consultant cardiologist. The exclusion criteria were: silent MI, comorbid chronic physical diseases (cancer, HIV, diabetes, renal problems, hypertension, etc.), psychological disorders and being on therapy for any chronic illness.

A group of 110 healthy individuals were also selected for comparison from among the patients' family members using convenience sampling. Of these 70 participated in the study; 19 did not agree to participate and 21 were excluded as they did not fulfil the required criteria. For the present research, healthy people were operationally defined as individuals who physically looked healthy and had not visited the physician for any chronic disease in the previous 12 months. The MI and healthy groups were not matched for any criteria.

\section{Instruments}

Two instruments were used in the study. Type $\mathrm{D}$ personality was measured using the 14-item type D scale (DS-14) developed by Denollet [5], which consists of 14 items: 7 items evaluating type-D personality in terms of negative affectivity and 7 items evaluating social inhibition. Subjects rated their responses on a 5-point Likert scale from 1 = false to $5=$ true, with a total score ranging from 7-35 for negative affectivity and social inhibition dimensions, with cutoff scores of 21 . The range of scores for type D personality was 14-70 with cutoff score of 42 . The alpha reliability values of negative affectivity and social inhibition in the present study were 0.71 and 0.61 respectively.

The World Health Organization quality of life questionnaire brief version (WHOQOL-BREF) [15] is a short version of the 100-item WHOQOL instrument, and consists of 26 items to 
measure overall QOL. The scoring is done on a 5-point Likert scale from 1 = very dissatisfied to $5=$ very satisfied. A high score on the scale is an indication of good QOL. The alpha reliability value of QOL in the present study was 0.93.

\section{Data collection}

The purpose of the study was explained to hospital authorities and permission was obtained. The selection criteria were followed by the consultant cardiologists for the selection of the patients. The participants were also briefed about the purpose of the study and assured about the confidentiality of the information provided by them. The protocol consisted of the demographic data sheet and 2 scales: the DS-14 and the WHOQOL-BREF. The questionnaires were personally distributed by the researchers to all respondents.

\section{Data analysis}

The chi-squared test was applied to examine the relation between the MI and healthy groups. Regression analysis was conducted to examine relationships among the 2 dimensions of type-D personality (negative affectivity and social inhibition) and QOL. The total score of the 2 facets of type-D personality served as independent variables and QOL as the dependent variable. The adjusted value of $R^{2}$ gives the more accurate picture about the fitness of model and was therefore used to explain the variance in QOL accounted for by the 2 dimensions.

\begin{tabular}{|c|c|c|c|c|c|c|}
\hline \multicolumn{7}{|c|}{$\begin{array}{l}\text { Table } 1 \text { Demographic characteristics of patients with myocardial infarction and } \\
\text { healthy people }\end{array}$} \\
\hline \multirow[t]{2}{*}{ Variable } & \multicolumn{2}{|c|}{$\begin{array}{l}\text { Healthy group } \\
\quad(n=70)\end{array}$} & \multicolumn{2}{|c|}{$\begin{array}{l}\text { Myocardial } \\
\text { infarction group } \\
(\boldsymbol{n}=\mathbf{8 0})\end{array}$} & \multirow[t]{2}{*}{$t$-value } & \multirow[t]{2}{*}{$P$-value } \\
\hline & No. & $\%$ & No. & $\%$ & & \\
\hline Sex & & & & & 1.32 & 0.09 \\
\hline Male & 38 & 54 & 49 & 61 & & \\
\hline Female & 32 & 46 & 31 & 39 & & \\
\hline Age group (years) & & & & & 1.87 & 0.17 \\
\hline $45-50$ & 17 & 24 & 11 & 14 & & \\
\hline $50-55$ & 21 & 30 & 38 & 47 & & \\
\hline $56-60$ & 32 & 46 & 31 & 39 & & \\
\hline
\end{tabular}

\section{Results}

\section{Background data}

A total of $80 \mathrm{MI}$ patients and 70 healthy individuals participated: 49 males (61\%) and 31 females (39\%) in the MI group and 38 males (54\%) and 32 females $(46 \%)$ in the healthy group (Table 1). There was no statistical difference between the MI patients and the healthy group on the basis of sex and age category.

\section{QOL and type D personality scores}

Table 2 shows that a significantly higher percentage of the MI group (71\%) scored positive for type-D personality compared with the healthy individuals (33\%). Similarly, significantly higher rates were found with respect to the negative affectivity (74\% versus 26\% respectively) and social inhibitions dimensions of type-D personality (66\% versus $37 \%$ respectively). The results also revealed a significantly higher number of MI patients with low QOL (below the cut-off score) as compared to healthy individuals (64\% versus $20 \%)$.

\section{Correlations}

The inter-correlations among type-D personality, its subscales negative affectivity and social inhibition, and QOL are shown on Table 3 . There was a significant positive correlation between type-D personality and negative affectivity $(r=0.93, P<0.01)$ and social inhibition scores $(r=0.90, P<0.01)$. Negative affectivity and social inhibition scores had a significant positive correlation with each other $(r=0.59, P<0.01)$. The results also showed a significant negative correlation between QOL and type-D personality scores $(r=-0.71, P$ $<0.01)$, as well as type-D components negative affectivity $(r=-0.64, P<0.01)$

\begin{tabular}{|c|c|c|c|c|c|c|c|}
\hline \multicolumn{8}{|c|}{$\begin{array}{l}\text { Table } 2 \text { Percentage of myocardial infarction patients and healthy people scoring positive for type D personality and poor } \\
\text { quality of life }\end{array}$} \\
\hline \multirow[t]{2}{*}{ Scale } & \multirow{2}{*}{$\begin{array}{c}\begin{array}{c}\text { Total } \\
(n=150)\end{array} \\
\text { No. }\end{array}$} & \multicolumn{2}{|c|}{$\begin{array}{l}\text { Healthy group } \\
\quad(n=70)\end{array}$} & \multicolumn{2}{|c|}{$\begin{array}{l}\text { Myocardial infarction } \\
\text { group } \\
(\boldsymbol{n}=\mathbf{8 0})\end{array}$} & \multirow[t]{2}{*}{$x^{2}$-value } & \multirow[t]{2}{*}{$P$-value } \\
\hline & & No. & $\%$ & No. & $\%$ & & \\
\hline Type-D personalitya & 80 & 23 & 33 & 57 & 71 & 3.51 & $<0.001$ \\
\hline Negative affectivity ${ }^{a}$ & 77 & 18 & 26 & 59 & 74 & 3.59 & $<0.001$ \\
\hline Social inhibition ${ }^{\mathrm{a}}$ & 79 & 26 & 37 & 53 & 66 & 3.08 & $<0.001$ \\
\hline Low quality of life ${ }^{\mathrm{b}}$ & 65 & 14 & 20 & 51 & 64 & 2.90 & 0.03 \\
\hline
\end{tabular}

${ }^{a}$ Type-D personality scale (cut-off scores: type D personality $=42$, negative affectivity $=21$, social inhibition $=21$ ).

${ }^{b}$ World Health Organization quality of life questionnaire brief version (cut-off score $=78$ ). 


\begin{tabular}{|c|c|c|c|c|}
\hline Variable & 1 & 2 & 3 & 4 \\
\hline Type-D personality & 0.81 & & & \\
\hline Negative affectivity & $0.93^{*}$ & 0.71 & & \\
\hline Social inhibition & $0.90^{*}$ & $0.59 *$ & 0.61 & \\
\hline Quality of life & $-0.71^{*}$ & $-0.64^{*}$ & $-0.67^{*}$ & 0.93 \\
\hline
\end{tabular}

${ }^{*} \mathrm{P}<0.01$ (boldface shows alpha reliability values of variables).

\begin{tabular}{lccccc}
\hline Table 4 Multiple regression analysis showing & impact & \multicolumn{4}{c}{ negative affectivity and social inhibition on quality of life } \\
\hline Model & $\boldsymbol{B}$ & SE & $\boldsymbol{\beta}$ & $\boldsymbol{t}$-value & $\boldsymbol{P}$-value \\
Negative affectivity & -1.01 & 0.32 & -0.34 & $-3.08^{*}$ & 0.003 \\
Social inhibition & -1.50 & 0.38 & -0.43 & $-3.88^{* *}$ & $<0.001$ \\
\hline
\end{tabular}

$\mathrm{R}^{2}=0.51$, adjusted $\mathrm{R}^{2}=0.50, F=40.43, \mathrm{P}<0.001$.

$S E=$ standard error.

and social inhibition $(r=-0.67, P<$ $0.01)$.

The results of the multiple regression analysis showed that both negative affectivity and social inhibition scores were significant predictors of QOL among cardiac patients. The value of adjusted $R^{2}=0.50$ shows that $50 \%$ of the variance in QOL was explained by type- $\mathrm{D}$ personality $(F=40.43, P<$ $0.001)$. At the same time beta values of $-0.34(P<0.01)$ and $-0.43(P<0.001)$ for negative affectivity and social inhibition respectively suggest that social inhibition had a greater adverse effect on cardiac patients' QOL than did negative affectivity (Table 4).

\section{Discussion}

The results of the study show that the rate of type-D personality was higher in MI patients compared with healthy individuals. These results are consistent with Pederson et al. who also showed a higher prevalence of Type-D personality among cardiac patients [16]. Regression analysis also revealed that type-D personality has a negative impact on QOL in cardiac patients and that the social inhibition component contributed more to low QOL compared with negative affectivity. Again, these agree with Pedersen et al. [16].

Possible reasons for such a finding lie in the characteristics of type-D personality. Those with negative affectivity are more prone towards anxiety and social inhibition, which leads to poor QOL [17]. Poor self-management, in particular inadequate consultation behaviour, in type-D patients may explain their increased risk for adverse clinical outcomes resulting in poor QOL [17]. Reporting somatic symptoms and seeking medical assistance is less common among MI patients with type-D personality, which further affects their QOL [17].

Type-D personality may be regarded as a psychopathological condition that can be referred for psychological evaluation. Psychological assessment for type-D personality can be helpful for developing health care plans for patients. Cognitive behavioural therapy, social skills training, emotional support, interpersonal psychotherapy and other stress reducing techniques can be deployed in type-D people to improve their quality of life.

This study had some limitations. First, a cross-sectional study design does not allow for the determination of cause and effect. Secondly, the study did not include information about the techniques and treatment used by the cardiologists and nurses. Thirdly, assessment of psychological distress was based on a self-report measure, although the sensitivity and specificity of this measure has been shown by others to be adequate. Finally, the study was based on data from outpatients and an unmatched sample of healthy people without taking a history of chronic physical and psychological problems.

Further research should be conducted on a larger sample on a longitudinal basis in order to confirm these results and to explore new dimensions of personality and health. Further studies on the psychological and biological features of type-D individuals may help develop treatment approaches to improve their psychological and physical health. It will be important to ascertain in epidemiological studies whether type $\mathrm{D}$ is not only a prognostic but also an etiological risk factor leading to the development of CVD. More diverse variables such as psychological distress, social support and clinical outcome together with its potential role in other somatic diseases and its prevalence in the general population should be considered to validate the effects of the type-D construct. 


\section{References}

1. Tazeen H et al. General practitioners' approach to hypertension in urban Pakistan: disturbing trends in practice. Hypertension, 2005, 1(11):1278-1283.

2. Khan SM et al. Knowledge of modifiable risk factors of heart disease among patients with acute myocardial infarction in Karachi, Pakistan: a cross sectional study. BMC Cardiovascular Disorders, 2006, 6:18.

3. Reddy KS et al. Cardiovascular risk profile in industrial populations across India: results from the CVD surveillance in industrial populations study. Indian Heart, 2005, 57:543.

4. Grande G et al Evaluation der deutschen Typ-D-Skala (DS14) und Pravalenz der Typ-D-Personlichkeit bei kardiologischen und psychosomatischen Patienten sowie Gesunden [Evaluation of the German type d scale (DS14) and prevalence of the type $d$ personality pattern in cardiological and psychosomatic patients and healthy subjects]. Psychotherapie, Psychosomatik, Medizinische Psychologie, 2004, 54:413-422.

5. Denollet J. DS14: standard assessment of negative affectivity, social inhibition, and type D personality. Psychosomatic Medicine, 2005, 67:89-97.

6. Habra ME et al. Type D personality is related to cardiovascular and neuroendocrine reactivity to acute stress. Journal of Psychosomatic Research, 2003, 55:235-245.

7. Schiffer AA et al. Failure to consult for symptoms of heart failure in patients with a type-D personality. Heart, 2007, 93(7):814-818.

8. Type "D" for distressed. Harvard Heart Letter, 2005, August (http://www.health.harvard.edu/newsweek/Type_D_for_ distressed.htm, accessed 20 July 2010).

9. Pedersen SS et al. Type D personality is associated with impaired health-related quality of life 7 years following heart transplantation. Journal of Psychosomatic Research, 2006, 61(6):791-795.

10. Reklaitiene R et al. Quality of life and perceived health among CHD patients and in general population. Acta Medica Lituanica, 2004, 11(2):39-44.

11. Cella D, Nowinski C. Measuring quality of life in chronic illness: the functional assessment of chronic illness therapy measurement system, Archives of Physical Medical Rehabilitation, 2002, 83(2):10-17.

12. Pedersen SS et al. Type-D personality but not implantable cardioverter-defibrillator indication is associated with impaired health-related quality of life 3 months post-implantation. Europace, 2007, 9(8):675-680

13. The atlas of heart diseases and stroke. Geneva, World Health Organization, 2006.

14. Nizami A et al. Relationship between anxiety, depression, psychological well-being and quality of life in diabetic patients having haemodialysis. Journal of the Pakistan Psychiatric Society, 2005, 2(2):80-84.

15. WHOQoL Group. The development of the World Health Organization quality of life assessment instrument (the WHOQoL). In: Orley J, Kuyken W, eds. Quality of life assessment: international perspectives. Heidleberg, Springer-Verlag, 1994

16. Pedersen SS et al. Type-D personality is a predictor of poor emotional quality of live in primary care heart failure patients independent of depressive symptoms and New York Heart Association functional class. Journal of Behavioral Medicine, 2010, 33(1):72-80.

17. Schiffer AA et al. Failure to consult for symptoms of heart failure in patients with a type-D personality. Heart, 2007, 93(7):814-818. 